\title{
SIFAT-SIFAT DASAR FUNGSI KARAKTERISTIK DARI DISTRIBUSI CAUCHY
}

\author{
NAZHMAL HUDA \\ Program Studi Magister Matematika, \\ Fakultas Matematika dan Ilmu Pengetahuan Alam, Universitas Andalas, \\ Kampus UNAND Limau Manis Padang, Indonesia, \\ email : nazhma.el.huda@gmail.com
}

\begin{abstract}
Abstrak. Pada paper ini diberikan fungsi karakteristik dari distribusi Cauchy. Selanjutnya, dengan menggunakan analisis diberikan proposisi yang menjelaskan sifat-sifat dasar fungsi karakteristik dari distribusi Cauchy.
\end{abstract}

Kata Kunci: Distribusi Cauchy, fungsi karakteristik, sifat dasar fungsi karakteristik

\section{Pendahuluan}

Distribusi Cauchy berasal dari penelitian yang dilakukan oleh matematikawan selama lebih dari tiga abad. Penelitian tersebut berawal dari kurva yang dipelajari oleh Pierre de Fermat pada tahun 1630 yang kemudian dipelajari oleh Sir Isac Newton, Gottfried Leibniz, Christian Huygens, Luigi Guido Grandi (1703), dan Maria Gaenata Agnesi (1748). Akhirnya, pada tahun 1853, Augustin Louis Cauchy memperkenalkan distribusi Cauchy baku dengan fungsi kepadatan peluang, $f(x)=\pi^{-1}\left(1+x^{2}\right)^{-1}$ dengan $x \in \mathbb{R}[2]$.

Secara umum, distribusi Cauchy merupakan distribusi peluang kontinu yang dinotasikan dengan $X \sim \operatorname{Cauchy}(a, b)$, dimana $X$ adalah peubah acak dan $a, b$ adalah parameter, memiliki fungsi kepadatan peluang sebagai berikut.

$$
f_{X}(x)=\frac{b}{\pi\left(b^{2}+(x-a)^{2}\right)},
$$

untuk setiap $-\infty<x<\infty,-\infty<a<\infty$, dan $b>0$ [3]. Distribusi Cauchy tidak memiliki nilai harapan, variansi, skewness, kurtosis, dan fungsi pembangkit momen, tetapi hanya memiliki fungsi karakteristik sebagai pencirinya [3].

Fungsi karakteristik dari suatu peubah acak $X$ dinotasikan dengan $\varphi_{X}(t)$ dan didefinisikan sebagai

$$
\varphi_{X}(t)=E\left[e^{i t X}\right],
$$

dimana $e^{i t X}=\cos (t X)+i \sin (t X)$ dan $i$ adalah bilangan imajiner [1,2]. Definisi fungsi karakteristik hampir sama dengan definisi fungsi pembangkit momen. Perbedaannya hanya pada keberadaan bilangan imajiner yang menunjukkan bahwa ruang lingkup fungsi karakteristik adalah ruang kompleks sedangkan fungsi pembangkit momen terbatas pada ruang riil saja. Dengan kata lain, fungsi karakteristik lebih 
bersifat umum daripada fungsi pembangkit momen. Oleh karena itu, suatu distribusi bisa saja tidak memiliki fungsi pembangkit momen, tetapi fungsi karakteristiknya selalu ada. Hal inilah yang berlaku pada distribusi Cauchy.

Adapun fungsi karakteristik memiliki sifat-sifat dasar sebagai berikut.

Proposisi 1.1. [2] Misalkan $\varphi_{X}(t)$ adalah fungsi karakteristik dari peubah acak $X$. $\operatorname{Maka} \varphi_{X}(0)=1$.

Proposisi 1.2. [2] Fungsi karakteristik ada untuk sebarang sebaran.

Proposisi 1.3. [2] Misalkan X suatu peubah acak. Maka fungsi karakteristik dari $-X$ adalah $\overline{\varphi_{X}(t)}$.

Proposisi 1.4. [2] Fungsi karakteristik $\varphi_{X}(t)$ adalah kontinu seragam.

Proposisi 1.5. [2] Misalkan X suatu peubah acak. Maka fungsi karakteristik dari $p+q X$ adalah $e^{i p t} \varphi_{X}(q t)$.

Proposisi 1.6. [2] Fungsi karakteristik $\varphi_{X}(t)$ dari peubah acak $X$ bernilai riil jika dan hanya jika peubah acak $X$ mempunyai sebaran yang simetrik terhadap ordinat $x=0$, yaitu $P(X>x)=P(X<x)$ untuk $x=0$.

Bentuk umum distribusi Cauchy diperoleh melalui sejarah yang panjang dan tidak lepas dari jasa para matematikawan. Hingga saat ini, masih banyak peneliti yang tertarik meneliti distribusi Cauchy ini. Untuk itu, pada tulisan ini dibahas tentang sifat-sifat dasar fungsi karakteristik dari distribusi Cauchy.

\section{Sifat-Sifat Dasar Fungsi Karakteristik dari Distribusi Cauchy}

Pada bagian ini, diberikan suatu teorema tentang fungsi karakteristik dari distribusi Cauchy yang dinyatakan sebagai berikut.

Teorema 2.1. [3] Jika $X$ adalah peubah acak berdistribusi Cauchy dengan parameter $a$ dan $b$, dinotasikan dengan $X \sim \operatorname{Cauchy}(a, b)$, maka peubah acak tersebut memiliki fungsi karakteristik

$$
\varphi_{X}(t)=e^{i a t} e^{-b|t|} .
$$

Mengacu pada kajian sifat-sifat dasar fungsi karakteristik oleh Lucas [2], maka fungsi karakteristik dari distribusi Cauchy memenuhi karakterisasi atau sifat-sifat dasar fungsi karakteristik sebagai berikut.

Proposisi 2.2. Fungsi karakteristik dari distribusi Cauchy adalah $\varphi_{X}(t)=$ $e^{i a t} e^{-b|t|} . \operatorname{Maka} \varphi_{X}(0)=1$.

Bukti. Dengan mensubstitusikan $t=0$ pada fungsi karakteristik dari distribusi Cauchy, diperoleh

$$
\varphi_{X}(t)=e^{i a(0)} e^{-b|0|}=1
$$

Proposisi 2.3. Jika $\varphi_{X}(t)$ adalah fungsi karakteristik dari peubah acak $X$ yang berdistribusi Cauchy maka fungsi karakteristik dari peubah acak $-X$ adalah $\overline{\varphi_{X}(t)}$. 
Bukti. Diberikan peubah acak $X$ berdistribusi Cauchy dengan fungsi kepadatan peluang sebagai berikut

$$
f_{X}(x)=\frac{b}{\pi\left(b^{2}+(x-a)^{2}\right)} .
$$

Misalkan $Y=-X$, maka diperoleh $\frac{d x}{d y}=-1$ dan mutlak Jacobian $|J|=1$. Sehingga peubah acak $Y$ mempunyai sebaran

$$
f(y)=f_{X}(y)|J|=\frac{b}{\pi\left(b^{2}+(-y-a)^{2}\right)} .
$$

Diperoleh sebaran dari peubah acak $-X$ adalah

$$
f(-x)=\frac{b}{\pi\left(b^{2}+(x-a)^{2}\right)} .
$$

Fungsi karakteristik dari peubah acak $-X$ adalah

$$
\varphi_{-X}(t)=E\left[e^{i t(-X)}\right]=\int_{-\infty}^{\infty} \frac{b e^{-i t x}}{\pi\left(b^{2}+(x-a)^{2}\right)} d x .
$$

Selanjutnya, nilai dari Persamaan (2.1) diperoleh dengan langkah sebagai berikut. Langkah 1. Untuk $a=0, b=1$, dan $t \geq 0$.

Perhatikan bahwa

$$
\oint_{C_{n}} \frac{e^{-i t z}}{1+z^{2}} d z=2 \pi i
$$

Fungsi

$$
f: z \longmapsto \frac{e^{-i t z}}{1+z^{2}}
$$

memiliki titik singular $z=-i$ dalam interior region $C_{n}$. Residu untuk $z=-i$

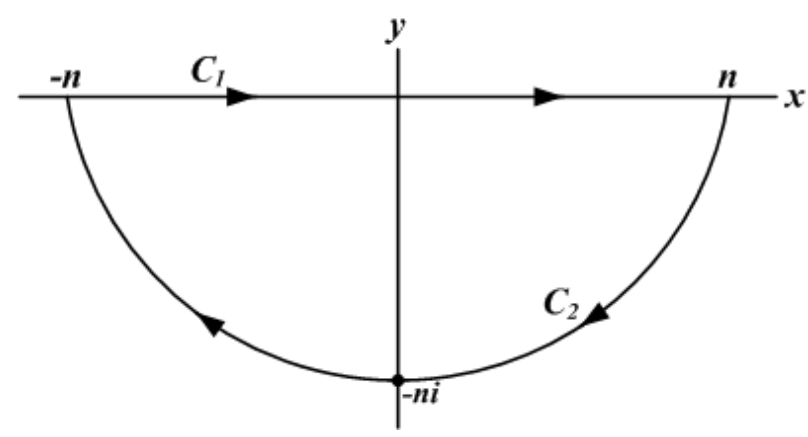

Gambar 1. Kontur pengintegralan peubah acak $-X$.

diberikan oleh

$$
\operatorname{Res}_{z=i}\left(\frac{e^{-i t z}}{1+z^{2}}\right)=\lim _{z \rightarrow-i}(z+i)\left(\frac{e^{-i t z}}{1+z^{2}}\right)=-\frac{e^{-t}}{2 i} .
$$


Karena kontur terletak di bawah sumbu $x$ maka Persamaan (2.2) sama-sama dikalikan negatif, sehingga diperoleh

$$
\begin{aligned}
-\oint_{C_{n}} \frac{e^{-i t z}}{1+z^{2}} d z & =-2 \pi i \operatorname{Res}_{z=i}\left(\frac{e^{-i t z}}{1+z^{2}}\right) \\
& =\pi e^{-t}, n>1 .
\end{aligned}
$$

Pengintegralan sepanjang kontur $C_{n}$ dapat diperoleh sebagai berikut

$$
\begin{aligned}
\pi e^{t} & =\oint_{C_{n}} \frac{e^{-i t z}}{1+z^{2}} d z \\
& =\int_{-n}^{n} \frac{e^{-i t x}}{1+x^{2}} d x+\int_{0}^{-\pi} \frac{e^{-i t n e^{i \beta}}}{1+n^{2} e^{2 i \beta}} n i e^{i \beta} d \beta .
\end{aligned}
$$

Hasil pengintegralan suku kedua pada sisi kanan konvergen ke nol jika $n \rightarrow \infty$. Perhatikan bahwa $\left|n^{2} e^{2 i \beta}+1\right| \geq n^{2}-1$, sehingga

$$
\left|\frac{e^{-i t n e^{i \beta}}}{1+n^{2} e^{2 i \beta}} n i e^{i \beta}\right| \leq \frac{n e^{n t \sin \beta}}{n^{2}-1} \leq \frac{n}{n^{2}-1} .
$$

Karena

$\left|\int_{0}^{-\pi} \frac{e^{-i t n e^{i \beta}}}{1+n^{2} e^{2 i \beta}} n i e^{i \beta} d \beta\right| \leq \int_{0}^{-\pi}\left|\frac{e^{-i t n e^{i \beta}}}{1+n^{2} e^{2 i \beta}} n i e^{i \beta}\right| d \beta \leq \int_{0}^{-\pi} \frac{n}{n^{2}-1} d \beta=\frac{\pi n}{n^{2}-1}$,

maka

$$
\lim _{n \rightarrow \infty} \int_{0}^{-\pi} \frac{e^{-i t n e^{i \beta}}}{1+n^{2} e^{2 i \beta}} n i e^{i \beta} d \beta=0 .
$$

Untuk $n \rightarrow \infty$ pada persamaan (2.3) diperoleh

$$
\int_{-\infty}^{\infty} \frac{e^{-i t x}}{1+x^{2}} d x=\pi e^{-t}
$$

Langkah 2. Untuk $a=0, b=1$, dan $t<0$.

Dengan mengikuti Langkah 1 diperoleh

$$
\int_{-\infty}^{\infty} \frac{e^{-i t x}}{1+x^{2}} d x=\pi e^{t}
$$

Langkah 3. Untuk kasus umum.

Berdasarkan Langkah 1 dan Langkah 2, maka

$$
\int_{-\infty}^{\infty} \frac{e^{-i t x}}{1+x^{2}} d x=\pi e^{-|t|}
$$

Untuk pengintegralan

$$
\int_{-\infty}^{\infty} \frac{e^{-i t x}}{b^{2}+(x-a)^{2}} d x
$$

terlebih dahulu substitusikan $x=v+a$ sehingga diperoleh

$$
\int_{-\infty}^{\infty} \frac{e^{-i t x}}{b^{2}+(x-a)^{2}} d x=e^{-i a t} \int_{-\infty}^{\infty} \frac{e^{-i t(v)}}{b^{2}+v^{2}} d v .
$$


Dengan mensubstitusikan $v=b u$ pada pengintegralan terakhir diperoleh

$$
\int_{-\infty}^{\infty} \frac{e^{-i t x}}{b^{2}+(x-a)^{2}} d x=\frac{\pi}{b} e^{-i t a} e^{-b|t|}
$$

Oleh karena itu,

$$
\int_{-\infty}^{\infty} \frac{b e^{-i t x}}{\pi\left(b^{2}+(x-a)^{2}\right)} d x=\frac{b}{\pi} \int_{-\infty}^{\infty} \frac{e^{-i t x}}{b^{2}+(x-a)^{2}} d x=e^{-i t a} e^{-b|t|} .
$$

Dengan demikian, diperoleh fungsi karakteristik dari peubah acak $-X$ berdistribusi Cauchy sebagai berikut.

$$
\varphi_{-X}(t)=e^{-i a t} e^{-b|t|}
$$

Perhatikan fungsi karakteristik dari peubah acak $X$ dan $-X$ berturut-turut sebagai berikut.

$$
\begin{aligned}
\varphi_{X}(t) & =e^{-b|t|}=[\cos (a t)+i \sin (a t)] e^{-b|t|}, \\
\varphi_{-X}(t) & =e^{-i a t} e^{-b|t|}=[\cos (a t)-i \sin (a t)] e^{-b|t|} .
\end{aligned}
$$

Berdasarkan Persamaan (2.4) dan (2.5), jelas bahwa $\varphi_{-X}(t)=\overline{\varphi_{X}(t)}$.

Proposisi 2.4. Jika peubah acak $X$ berdistrbusi Cauchy, maka fungsi karakteristik dari peubah acak $p+q X$ adalah $e^{i p t} \varphi_{X}(q t)$.

Bukti. ungsi karakteristik dari $p+q X$ ditentukan sebagai berikut:

$$
\begin{aligned}
\varphi_{p+q X}(t) & =E\left[e^{i t(p+q X)}\right] \\
& =e^{i p t} \int_{-\infty}^{\infty} \frac{b e^{i q t x}}{\pi\left(b^{2}+(x-a)^{2}\right)} d x
\end{aligned}
$$

Terlebih dahulu ditentukan nilai dari

$$
\int_{-\infty}^{\infty} \frac{b e^{i q t x}}{\pi\left(b^{2}+(x-a)^{2}\right)} d x
$$

dengan langkah-langkah sebagai berikut.

Langkah 1. Untuk $a=0, b=1$, dan $t \geq 0$.

Perhatikan bahwa

$$
\oint_{C_{n}} \frac{e^{i q t z}}{1+z^{2}} d z=2 \pi i
$$

Fungsi

$$
f: z \longmapsto \frac{e^{i q t z}}{1+z^{2}}
$$

memiliki titik singular $z=i$ dalam interior region $C_{n}$.

Residu untuk $z=i$ diberikan oleh

$$
\begin{aligned}
\operatorname{Res}_{z=i}\left(\frac{e^{i q t z}}{1+z^{2}}\right) & =\lim _{z \rightarrow i}(z-i)\left(\frac{e^{i q t z}}{1+z^{2}}\right) \\
& =\frac{e^{-q t}}{2 i} .
\end{aligned}
$$




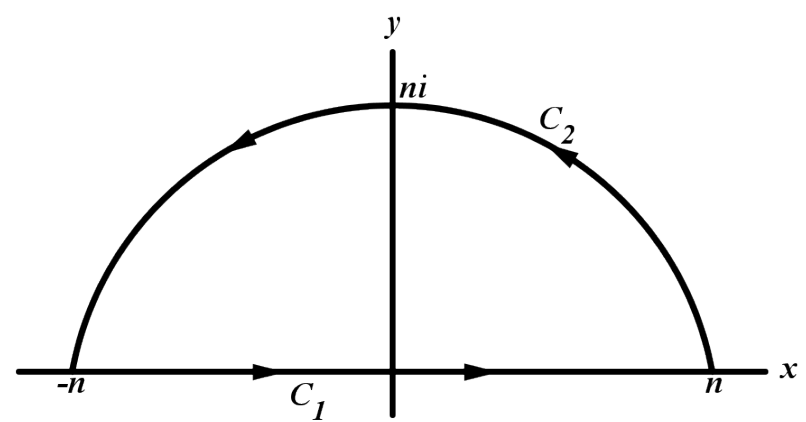

Gambar 2. Kontur pengintegralan peubah acak $p+q X$.

Oleh karena itu,

$$
\begin{aligned}
\oint_{C_{n}} \frac{e^{i q t z}}{1+z^{2}} d z & =2 \pi i \operatorname{Res}_{z=i}\left(\frac{e^{i q t z}}{1+z^{2}}\right) \\
& =\pi e^{-q t}, n>1
\end{aligned}
$$

Pengintegralan sepanjang kontur $C_{n}$ dapat diperoleh sebagai berikut

$$
\begin{aligned}
\pi e^{-q t} & =\oint_{C_{n}} \frac{e^{i q t z}}{1+z^{2}} d z \\
& =\int_{-n}^{n} \frac{e^{i q t x}}{1+x^{2}} d x+\int_{0}^{\pi} \frac{e^{i q t n e^{i \beta}}}{1+n^{2} e^{2 i \beta}} n i e^{i \beta} d \beta .
\end{aligned}
$$

Hasil pengintegralan suku kedua pada sisi kanan konvergen ke nol jika $n \rightarrow \infty$. Perhatikan bahwa $\left|n^{2} e^{2 i \beta}+1\right| \geq n^{2}-1$, sedemikian sehingga

$$
\left|\frac{e^{i q t n e^{i \beta}}}{1+n^{2} e^{2 i \beta}} n i e^{i \beta}\right| \leq \frac{n e^{-n q t \sin \beta}}{n^{2}-1} \leq \frac{n}{n^{2}-1} .
$$

Karena

$$
\left|\int_{0}^{\pi} \frac{e^{i q t n e^{i \beta}}}{1+n^{2} e^{2 i \beta}} n i e^{i \beta} d \beta\right| \leq \int_{0}^{\pi}\left|\frac{e^{i q t n e^{i \beta}}}{1+n^{2} e^{2 i \beta}} n i e^{i \beta}\right| d \beta \leq \int_{0}^{\pi} \frac{n}{n^{2}-1} d \beta=\frac{\pi n}{n^{2}-1},
$$

maka

$$
\lim _{n \rightarrow \infty} \int_{0}^{\pi} \frac{e^{i q t n e^{i \beta}}}{1+n^{2} e^{2 i \beta}} n i e^{i \beta} d \beta=0 .
$$

Untuk $n \rightarrow \infty$ pada Persamaan (2.6) diperoleh

$$
\int_{-\infty}^{\infty} \frac{e^{i q t x}}{1+x^{2}} d x=\pi e^{-q t}
$$

Langkah 2. Untuk $a=0, b=1$, dan $t<0$.

Dengan mengikuti Langkah 1 diperoleh

$$
\int_{-\infty}^{\infty} \frac{e^{i q t x}}{1+x^{2}} d x=\pi e^{q t}
$$


Langkah 3. Untuk kasus umum.

Berdasarkan Langkah 1 dan Langkah 2, maka

$$
\int_{-\infty}^{\infty} \frac{e^{i q t x}}{1+x^{2}} d x=\pi e^{-q|t|}
$$

Untuk pengintegralan

$$
\int_{-\infty}^{\infty} \frac{e^{i q t x}}{b^{2}+(x-a)^{2}} d x
$$

terlebih dahulu substitusikan $x=v+a$ sehingga diperoleh

$$
\int_{-\infty}^{\infty} \frac{e^{i q t x}}{b^{2}+(x-a)^{2}} d x=e^{i a q t} \int_{-\infty}^{\infty} \frac{e^{i q t(v)}}{b^{2}+v^{2}} d v
$$

Dengan mensubstitusikan $v=b u$ pada pengintegralan terakhir diperoleh

$$
\int_{-\infty}^{\infty} \frac{e^{i q t x}}{b^{2}+(x-a)^{2}} d x=\frac{\pi}{b} e^{i a q t} e^{-b q|t|}
$$

Oleh karena itu,

$$
\int_{-\infty}^{\infty} \frac{e^{i q t x} b}{\pi\left(b^{2}+(x-a)^{2}\right)} d x=\frac{b}{\pi} \int_{-\infty}^{\infty} \frac{e^{i q t x}}{b^{2}+(x-a)^{2}} d x=e^{i a q t} e^{-b q|t|} .
$$

Dengan demikian, diperoleh fungsi karakteristik dari $p+q X \sim \operatorname{Cauchy}(a, b)$ sebagai berikut.

$$
\varphi_{X}(t)=e^{i a q t} e^{-b q|t|}
$$

Proposisi 2.5. Fungsi karakteristik dari distribusi Cauchy, $\varphi_{X}(t)=e^{i a t} e^{-b|t|}$, bernilai riil jika dan hanya jika peubah acak $X$ mempunyai sebaran yang simetrik terhadap ordinat $x=0$, yaitu $P(X>x)=P(X<x)$ untuk $x=0$.

Bukti. Peubah acak $X$ mempunyai sebaran yang simetrik terhadap ordinat $x=0$ jika dan hanya jika $\varphi_{X}(t)=\overline{\varphi_{X}(t)}$. Berdasarkan Persamaan (2.4) dan (2.5) diperoleh

$$
\varphi_{X}(t)=[\cos (a t)+i \sin (a t)] e^{-b|t|} \neq[\cos (a t)-i \sin (a t)] e^{-b|t|}=\varphi_{-X}(t)=\overline{\varphi_{X}(t)} .
$$

Dengan demikian, jelas peubah acak $X$ tidak mempunyai sebaran yang simetrik terhadap ordinat $x=0$ sehingga fungsi karakteristik dari distribusi Cauchy tidak hanya mempunyai bagian riil.

\section{Kekontinuan Seragam Fungsi Karakteristik dari Distribusi Cauchy}

Pada bagian ini diuraikan secara khusus kekontinuan seragam fungsi karakteristik dari distribusi Cauchy yang merupakan salah satu sifat dasar fungsi karakteristik yang telah dijelaskan sebelumnya. Kekontinuan seragam fungsi karakteristik dari distribusi Cauchy dinyatakan sebagai berikut.

Proposisi 3.1. Fungsi karakteristik dari distribusi Cauchy, $\varphi_{X}(t)=e^{i a t} e^{-b|t|}$, bersifat kontinu seragam. 
Bukti. Misalkan $\varphi_{X}(t)=e^{i a t} e^{-b|t|}$ dan $h=s-t$ dimana $s>t$, maka akan ditunjukkan bahwa untuk setiap $\varepsilon>0$ terdapat $\delta>0$ sedemikian sehingga $\mid \varphi_{X}(s)-$ $\varphi_{X}(t)|=| e^{i a s} e^{-b|s|}-e^{i a t} e^{-b|t|} \mid<\varepsilon$ untuk $|s-t|<\delta$. Perhatikan bahwa

$$
\begin{aligned}
\left|\varphi_{X}(s)-\varphi_{X}(t)\right| & =\left|e^{i a s} e^{-b|s|}-e^{i a t} e^{-b|t|}\right| \\
& =\left|i a(s-t)+b(|s|-|t|)-\frac{a^{2}-b^{2}}{2}\left(s^{2}-t^{2}\right)-i a b(s|s|-t|t|)+\ldots\right| \\
& =\left|(s-t)\left[i a+b-\frac{a^{2}-b^{2}}{2}(s+t)+i a b(|s|-|t|)+\ldots\right]\right|
\end{aligned}
$$

Jadi, untuk $h \longrightarrow 0,\left|\varphi_{X}(h+t)-\varphi_{X}(t)\right| \longrightarrow 0$, dan $|s-t| \longrightarrow 0$. Hal ini menunjukkan $\delta$ bergantung pada $\varepsilon$, dimana $\left|\varphi_{X}(h+t)-\varphi_{X}(t)\right|<\varepsilon$ untuk $|s-t|<\delta$.

\section{Kesimpulan}

Distribusi Cauchy merupakan distribusi peluang kontinu yang hanya memiliki satu penciri yaitu fungsi karakteristik. Fungsi karakteristik dari distribusi Cauchy dinyatakan sebagai

$$
\varphi_{X}(t)=e^{i a t} e^{-b|t|} .
$$

Adapun sifat-sifat dasar fungsi karakteristik dari distribusi Cauchy adalah

(1) Fungsi karakteristik dari distribusi Cauchy saat $t=0$ adalah 1.

(2) Jika $\varphi_{X}(t)=e^{i a t} e^{-b|t|}$ adalah fungsi karakteristik dari peubah acak $X$ yang berdistribusi Cauchy maka fungsi karakteristik dari peubah acak $-X$ adalah $\overline{\varphi_{X}(t)}=e^{-i a t} e^{-b|t|}$

(3) Jika $X$ adalah suatu peubah acak berdistrbusi Cauchy, maka fungsi karakteristik dari $p+q X$ adalah $\varphi_{p+q X}(t)=e^{i p t} \varphi_{X}(q t)$.

(4) Distribusi Cauchy tidak menyebar simetrik terhadap ordinat $x=0$, sedemikian sehingga fungsi karakteristik dari distribusi Cauchy tidak hanya bernilai riil.

(5) Fungsi karakteristik dari distribusi Cauchy adalah kontinu seragam.

\section{Daftar Pustaka}

[1] Churchill, R. V. dan J. W. Brown. 1996. Complex Variables and Applications, Sixth Edition. McGraw-Hill, Inc, Singapore

[2] Lukacs, E. 1970. Characteristic Functions, Second Edition. Griffin, London.

[3] Oktasari, L., D. Devianto, dan Maiyastri. 2015. Penentuan Konvolusi Distribusi Cauchy dengan Menggunakan Fungsi Karakteristik. Prosiding Semnas Mat-PMat STKIP PGRI Sumatera Barat.

[4] Stigler, S. M. 1974. Studies in the History of Probability and Statistics XXXIII. Cauchy and the Witch of Agnesi: An Historical Note on the Cauchy Distribution. Biometrika, Vol. $61: 375-380$ 